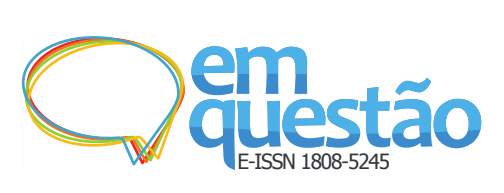

\title{
O desempenho das universidades brasileiras em rankings internacionais ${ }^{1}$
}

\author{
Solange Maria dos Santos \\ Doutora; Universidade de São Paulo (USP); São Paulo, SP, Brasil; \\ solangesan@gmail.com \\ Daisy Pires Noronha \\ Doutora; Universidade de São Paulo (USP); São Paulo, SP, Brasil; \\ daisynor@usp.br
}

\begin{abstract}
Resumo: Em menos de dez anos, os rankings universitários mundiais tornaramse mais potentes e têm alcançado importância crescente, influenciando políticas, processos avaliativos, decisões de investimento e reestruturação institucional. Com isso, o objetivo do presente estudo foi analisar o desempenho das universidades brasileiras em três dos principais rankings internacionais: ARWU; $T H E$ e $Q S$. A análise revelou que as universidades brasileiras destacam-se por sua pontuação no indicador volume de publicações e em alguns casos também no indicador reputação entre acadêmicos e empregadores. Pontuações mais baixas foram obtidas nos indicadores que medem impacto por meio de publicações altamente citadas, indicador que costuma ter alto peso na maioria dos rankings. Conclui-se que apesar desses resultados é importante considerar que as classificações internacionais são, de modo geral, homogeneizadoras, de maneira que muitas particularidades, nuances e bolsões de excelência em áreas específicas não são capturados pelos rankings internacionais quando as instituições são avaliadas como um todo.
\end{abstract}

Palavras-Chave: Universidades brasileiras. Instituições de Ensino Superior. Rankings universitários.

\section{Introdução}

Nos últimos 10 anos, constatou-se um aumento considerável do número de sistemas de ranqueamento global de universidades, fenômeno que tem despertado interesse entre os estudiosos da área de educação, bem como de outros atores envolvidos no sistema de ensino superior. Todos os anos, vários tipos de rankings universitários são publicados e atualizados por órgãos governamentais, instituições acadêmicas, revistas e jornais eminentes, tornandose tema de debate e de interesse mundial.

Embora o interesse por essas classificações seja relativamente recente, os rankings de universidades não são um fenômeno novo. $\mathrm{O}$ primeiro ranking 
nacional de universidades foi publicado em 1983 pelo US News \& World Report $^{2}$ como um relatório de avaliação das melhores faculdades americanas (DILL, 2006). Foi com o US News \& World Report Ranking que pela primeira vez a informação sobre a avaliação das universidades tornou-se facilmente acessível a alunos de graduação em potencial e seus pais, promovendo assim algumas mudanças nos hábitos dos consumidores de informação sobre avaliação da qualidade das universidades. Depois dos Estados Unidos, em 1990 o Reino Unido também passou a produzir um ranking para diferenciar as melhores escolas de negócios. Nesse período, a comunidade científica em particular e a sociedade em geral deram pouca atenção ao fato. Somente no começo do século XXI que se constatou uma verdadeira obsessão mundial com rankings universitários, quando em 2003 uma equipe de pesquisadores da Shanghai Jiao Tong University se propôs a averiguar o quão distante as universidades chinesas estavam das universidades de "classe mundial". Foi somente a partir da publicação do Academic Ranking of World Universities (ARWU) que os rankings internacionais de universidades começaram a proliferar e a atrair considerável atenção da sociedade em geral e da comunidade científica em particular.

A popularidade alcançada em nível mundial pelos rankings de universidades reflete o grau de globalização e de internacionalização da educação superior. Dessa forma, os rankings se mostram úteis a partir do momento em que políticos os utilizam regularmente como uma das medidas da força econômica e das aspirações de seus países, universidades podem utilizálos para ajudar a estabelecer ou definir objetivos que meçam seu desempenho em relação a diversos indicadores, e professores valem-se dos mesmos para fortalecer sua reputação profissional e seu status (HAZELKORN, 2010; SALMI E SAROYAN, 2007; SAISANA, D’HOMBRES E SALTELLI, 2011). O que começou como produto para consumidores, dirigido a alunos de graduação locais, tornou-se uma demonstração da competição global e também um indutor da "batalha por excelência", conforme denomina Hazelkorn (2010). Um relatório recente elaborado pela Associação Universitária Europeia (European University Association) analisa as principais classificações existentes e destaca o 
caráter excludente dos rankings mundiais, revelando que os mais populares incluem apenas de $1 \%$ a 3\% das instituições (700-1200 universidades), cerca de 18 mil instituições de nível superior do mundo, desconsiderando e até mesmo excluindo a grande maioria das universidades que neles nunca apareceram (RAUHVARGERS, 2011; RAUHVARGERS, 2013; ALTBACH, 2010). Nesse contexto, mesmo as instituições de ensino superior que não estão presentes em rankings globais são afetadas pela popularidade destes. Essas instituições se preocupam com o fato de ficarem à margem dessas classificações ou de serem ignoradas por alunos em potencial, pelo governo e por outros elementos envolvidos direta ou indiretamente com o ensino superior.

Apesar da efervescência e do amplo debate internacional a respeito do impacto dos rankings de universidades nos sistemas de ensino superior de vários países e da extensa cobertura do tema pela mídia, estudos sobre os sistemas de classificação são praticamente inexistentes no Brasil. Em função disso, partindo da importância e do impacto que os rankings passaram a ter sobre universidades, grupos interessados e sociedade em geral, o presente trabalho tem por objetivo analisar os resultados do desempenho das universidades brasileiras nas edições de 2014 de três dos mais destacados rankings internacionais: Academic Ranking of World Universities (ARWU), The Times Higher Education (THE) e QS World University Rankings.

\section{Metodologias}

As informações relacionadas aos rankings universitários internacionais foram coletadas a partir de seus respectivos sites oficiais. As classificações das universidades brasileiras nos rankings analisados no período de janeiro de 2013 a dezembro de 2014, foram coletadas e armazenados, ano a ano, em planilhas Excel. A análise mais detalhada do desempenho das universidades brasileiras foi realizada, para a edição de 2014, nos seguintes rankings internacionais que, dentre outros, classificam as principais universidades do mundo. Cada um deles com sua própria metodologia, a seguir. 


\subsection{Academic Ranking of World Universities (ARWU)}

A primeira edição do ranking ARWU foi produzida em 2003 pelo Center for World-Class Universities $(C W C U)^{3}$, da Shanghai Jiao Tong University e desde então o ranking tem sido publicado anualmente no mês de agosto. Considerado o primeiro ranking de universidades em nível mundial, o ARWU revelou que a maioria das universidades classificadas nas primeiras posições pertenciam aos Estados Unidos e ao Reino Unido (RAUHVARGERS, 2011).

Ancorado em uma metodologia centrada em indicadores bibliométricos o ARWU classifica as 500 universidades que mais se destacam em termos de desempenho acadêmico e pesquisa. O ranking emprega cinco indicadores (Quadro 1), que medem a produção científica em quantidade e qualidade: o número de artigos indexados na base WoS (PUB); o número de pesquisadores com elevado nível de citações (HiCi); os antigos alunos ou professores que receberam o Prêmio Nobel ou a Medalha Fields seu equivalente em Matemática (Alumni e Awards); a publicação em revista de grande prestígio (N\&S). Há um sexto indicador composto que agrega os anteriores e os pondera pelo número de professores da instituição com dedicação em tempo integral (PCP). Por fim, os seis indicadores são agregados e se atribui uma pontuação numérica final em função da melhor instituição, que recebe 100 pontos (ACADEMIC RANKING WORLD UNIVERSITIES, 2014b). 
Quadro 1 - Indicadores utilizados na elaboração do ranking ARWU - 2014

\begin{tabular}{|c|c|c|c|}
\hline CRITÉRIOS & INDICADOR & \multicolumn{1}{|c|}{ DESCRIÇÃO } & PESO \\
\hline $\begin{array}{c}\text { Qualidade de } \\
\text { Ensino }\end{array}$ & Alumni & $\begin{array}{l}\text { Número total de Alunos e ex-alunos, ganhadores } \\
\text { de prêmios Nobel e medalhas Fields (maior } \\
\text { honraria entre os matemáticos). }\end{array}$ & $10 \%$ \\
\hline \multirow{2}{*}{$\begin{array}{c}\text { Qualidade do } \\
\text { Corpo do } \\
\text { docente }\end{array}$} & Awards & $\begin{array}{l}\text { Membros do corpo docente da instituição } \\
\text { ganhadores de prêmios Nobel em física, } \\
\text { química, medicina e economia e Medalha Fields }\end{array}$ & $20 \%$ \\
\cline { 2 - 4 } & $\mathrm{HiCi}$ & $\begin{array}{l}\text { Número de pesquisadores da lista dos 250 mais } \\
\text { citados nas 21 áreas do conhecimento. }\end{array}$ & $20 \%$ \\
\hline \multirow{2}{*}{$\begin{array}{c}\text { Resultados de } \\
\text { pesquisa }\end{array}$} & N\&S & $\begin{array}{l}\text { Autores de artigos publicados na Nature e na } \\
\text { Science nos últimos 5 anos }\end{array}$ & $20 \%$ \\
\cline { 2 - 4 } & PUB & $\begin{array}{l}\text { Quantidade de artigos científicos publicados nas } \\
\text { bases Science Citation Index Expanded-(SCIE) e } \\
\text { Social Sciences Science Citation Index (SSCI) } \\
\text { da WoS da Thomson Reuters no ano anterior. }\end{array}$ & $20 \%$ \\
\hline $\begin{array}{c}\text { Tamanho da } \\
\text { Instituição }\end{array}$ & PCP & $\begin{array}{l}\text { Desempenho acadêmico de acordo com o } \\
\text { tamanho da instituição. }\end{array}$ & $10 \%$ \\
\hline
\end{tabular}

Fonte: Adaptado de Academic Ranking World Universities (2014b)

Para produzir o ranking anual o ARWU considera cerca de 2 mil universidades, sendo que 1.200 são analisadas, mas apenas as 500 primeiras universidades são ranqueadas e publicadas na versão anual do ranking (ACADEMIC RANKING WORLD UNIVERSITIES, 2014b; ACADEMIC RANKING WORLD UNIVERSITIES, 2014c).

\subsection{Times Higher Education - World University Rankings (THE)}

Outro ranking de considerável prestígio no cenário internacional é o Times Higher Education (THE), suplemento do jornal britânico The Times que, em 2004 começou a publicar seu próprio ranking, relacionando as 200 melhores universidades do mundo ${ }^{4}$. Atualmente o THE ranqueia as 400 melhores universidades do mundo.

Diferente do ARWU, o THE foi desde o início elaborado com base em duas avaliações distintas. Uma análise qualitativa (prestígio e reputação) realizada por meio de pesquisas de opinião aplicadas a dois grupos considerados capazes de fornecer pontos de vista relevantes: acadêmicos e empregadores. E outra análise quantitativa, baseada em indicadores estruturais de desempenho. 
Com base nos 13 indicadores adotados, o ranking THE se propõe a analisar o desempenho global das universidades em suas missões básicas: ensino, pesquisa, influência em pesquisa (citações-impacto), perspectiva internacional e transferência de conhecimento-inovação (Quadro 2).

Quadro 2 - Indicadores utilizados na elaboração do ranking THE - 2014

\begin{tabular}{|c|c|c|c|}
\hline CRITÉRIOS & INDICADOR & DESCRIÇÃO & PESO \\
\hline \multirow{5}{*}{$\begin{array}{l}\text { Ensino: } \\
\text { Ambiente de } \\
\text { aprendizado }\end{array}$} & Reputação Acadêmica & $\begin{array}{l}\text { Resultados obtidos por meio da } \\
\text { pesquisa de opinião entre os } \\
\text { acadêmicos, sobre o prestígio e } \\
\text { reputação das instituições em ensino. }\end{array}$ & $15 \%$ \\
\hline & Doutores titulados & $\begin{array}{l}\text { Número de doutorados titulados em } \\
\text { relação ao tamanho do corpo docente } \\
\text { da instituição. }\end{array}$ & $6 \%$ \\
\hline & Alunos/Staff acadêmico & $\begin{array}{l}\text { Proporção entre o número de alunos } \\
\text { de graduação admitidos em relação ao } \\
\text { número de docentes. }\end{array}$ & $4,5 \%$ \\
\hline & Orçamento & $\begin{array}{l}\text { Relação entre o orçamento da } \\
\text { instituição e o número de docentes. }\end{array}$ & $2,25 \%$ \\
\hline & Doutorados/Bacharelados & $\begin{array}{l}\text { Proporção entre o número de } \\
\text { doutorados e de bacharelados } \\
\text { concedidos. }\end{array}$ & $2,25 \%$ \\
\hline \multirow{3}{*}{$\begin{array}{l}\text { Pesquisa: } \\
\text { reputação, } \\
\text { orçamento e } \\
\text { volume }\end{array}$} & Reputação em Pesquisa & $\begin{array}{l}\text { Resultados obtidos por meio da } \\
\text { pesquisa de opinião entre os } \\
\text { acadêmicos, sobre o prestígio e } \\
\text { reputação das instituições em } \\
\text { pesquisa. }\end{array}$ & $18 \%$ \\
\hline & Investimento em Pesquisa & $\begin{array}{l}\text { Relação entre orçamento destinado à } \\
\text { pesquisa e o número de docentes. }\end{array}$ & $6 \%$ \\
\hline & Publicações & $\begin{array}{l}\text { Relação entre a quantidade de } \\
\text { documentos publicados (indexados na } \\
\text { WoS da Thomson Reuters) e entre o } \\
\text { número de docentes. }\end{array}$ & $6 \%$ \\
\hline $\begin{array}{l}\text { Citações: } \\
\text { influência da } \\
\text { Pesquisa }\end{array}$ & Citações & $\begin{array}{l}\text { Número de citações recebidas na WoS } \\
\text { nos últimos } 5 \text { anos. }\end{array}$ & $30 \%$ \\
\hline \multirow{3}{*}{$\begin{array}{l}\text { Perspectiva } \\
\text { internacional }\end{array}$} & $\begin{array}{c}\text { Estudantes estrangeiros e } \\
\text { nacionais }\end{array}$ & $\begin{array}{l}\text { Proporção de estudantes estrangeiros } \\
\text { em relação ao número de estudantes } \\
\text { nacionais da instituição. }\end{array}$ & $2,5 \%$ \\
\hline & $\begin{array}{c}\text { Docentes estrangeiros e } \\
\text { nacionais }\end{array}$ & $\begin{array}{l}\text { Proporção de docentes estrangeiros } \\
\text { em relação aos docentes nacionais da } \\
\text { instituição }(2,5 \%) \text {. }\end{array}$ & $2,5 \%$ \\
\hline & Colaboração internacional & $\begin{array}{l}\text { Número de artigos científicos } \\
\text { produzidos com um ou mais coautores } \\
\text { estrangeiros. }\end{array}$ & $2,5 \%$ \\
\hline $\begin{array}{l}\text { Captação de } \\
\text { Recursos da } \\
\text { Indústria: } \\
\text { Inovação }\end{array}$ & Recursos da indústria & $\begin{array}{l}\text { Mede o peso de recursos destinados à } \\
\text { pesquisa provenientes da indústria em } \\
\text { relação ao número de acadêmicos. }\end{array}$ & $2,5 \%$ \\
\hline
\end{tabular}

Fonte: Adaptado de Times Higher Education (2014b) 
Somente instituições que tenham publicado um mínimo de 200 trabalhos de pesquisa por ano, nos últimos cinco anos, são consideradas para análise no THE ranking global.

\subsection{QS World University Rankings (QS)}

Em setembro de 2010, após o rompimento da parceria na elaboração do Times Higher Education, de 2004 a 2009, a Quacquarelli Symonds, empresa britânica especializada em educação e estudos no exterior, aconselhando estudantes em suas carreiras, decidiu seguir utilizando a metodologia original, que era empregada na elaboração do THE, para produzir de maneira independente, seu próprio ranking, o QS University Rankings. Este ranking é divulgado em parceria com a US News \& World Report de Washington, D.C., Chosun Ilbo Jornal da Coréia do Sul, The Sunday Times do Reino Unido e o francês Nouvel Observateur.

Assim como o THE, o ranking QS combina tanto critérios mais objetivos (informação quantitativa) quanto critérios baseados em reputação. Com base nos seis indicadores utilizados na elaboração do QS, as universidades são analisadas considerando quatro critérios: reputação, qualidade de ensino, impacto e orientação internacional.

Quadro 3 - Indicadores utilizados na elaboração do ranking QS World University Rankings 2014

\begin{tabular}{|c|c|l|c|}
\hline CRITÉRIOS & INDICADOR & \multicolumn{1}{|c|}{ DESCRIÇÃO } & PESO \\
\hline \multirow{2}{*}{ Reputação } & Reputação acadêmica & $\begin{array}{l}\text { Pontos obtidos pelas instituições na } \\
\text { pesquisa global "Peer review" de opinião } \\
\text { dos pares acadêmicos }\end{array}$ & $40 \%$ \\
\cline { 2 - 4 } & $\begin{array}{c}\text { Reputação entre } \\
\text { empregadores }\end{array}$ & $\begin{array}{l}\text { Pontos obtidos pelas instituições na } \\
\text { pesquisa segundo avaliação dos } \\
\text { empregadores }\end{array}$ & $10 \%$ \\
\hline $\begin{array}{c}\text { Qualidade do } \\
\text { Ensino }\end{array}$ & $\begin{array}{c}\text { Estudantes por } \\
\text { professor }\end{array}$ & $\begin{array}{l}\text { Proporção do número de estudantes por } \\
\text { professor da instituição. }\end{array}$ & $20 \%$ \\
\hline Impacto & $\begin{array}{c}\text { Citações por docente } \\
\text { período de cinco anos dividido pelo } \\
\text { número de doentes da instituição. }\end{array}$ & $20 \%$ \\
\hline $\begin{array}{c}\text { Orientação } \\
\text { Internacional }\end{array}$ & $\begin{array}{c}\text { Professores } \\
\text { estrangeiros }\end{array}$ & $\begin{array}{l}\text { Proporção de pesquisadores estrangeiros } \\
\text { parte do corpo docente da instituição }\end{array}$ & $5 \%$ \\
\cline { 2 - 4 } & estrangeiros & $\begin{array}{l}\text { Proporção de estudantes estrangeiros } \\
\text { matriculados na instituição. }\end{array}$ & $5 \%$ \\
\hline
\end{tabular}

Fonte: Adaptado de Quacquarelli Symonds (2014b) 
O QS avalia mais de 3000 universidades do mundo e dentre estas, classifica 800 instituições de ensino superior. Para compor a lista de universidades analisadas para a elaboração de seus rankings, o QS considera as universidades incluídas no seu banco com base em alguns critérios: desempenho em rankings nacionais; desempenho na pesquisa de opinião com acadêmicos e empregadores; balanceamento geográfico com base no número de instituições de cada país ou região, e a apresentação direta - algumas instituições solicitam, diretamente à equipe do QS, sua inclusão na avaliação (QUACQUARELLI SYMONDS, 2014c).

Embora não seja o objeto de estudo desse trabalho, cabe mencionar que além das classificações em nível global, todos os rankings analisados produzem também classificações por áreas do conhecimento e disciplinas. De modo geral, a produção dos rankings por área segue o mesmo processo de elaboração do ranking global, seja em relação à metodologia aplicada ou aos indicadores empregados para ranquear as instituições. A diferença está apenas na atribuição de pesos distintos aos indicadores, calibrados de acordo com as especificidades de cada área. Por essa razão, os rankings por áreas costumam destacar a especialização e a fortaleza de universidades que muitas vezes não são visíveis aos rankings globais. Em estudo recente, Santos (2015) demonstra que as universidades brasileiras alcançam performance muito melhor quando avaliadas em um número limitado de campos e áreas de estudos.

\section{Desempenho das universidades brasileiras nos rankings (edição de 2014)}

Com o surgimento dos rankings, as universidades em geral passaram a competir em nível global, procurando alcançar as primeiras posições nas classificações internacionais. No entanto, a mobilidade das universidades nos posicionamentos dos rankings está à mercê dos objetivos ou razões que lhes dão origem, isto é, cada ranking apresenta a sua visão do que considera qualidade ao estabelecer um conjunto de critérios amplos. Assim, alguns indicadores estabelecidos podem dificultar essa mobilidade como o número de Prêmios Nobel e Medalhas Fields que diferenciam as universidades nas primeiras 20 posições. 
O Quadro 4 lista as universidades que alcançaram as 20 primeiras posições na edição de 2014 nos três rankings analisados.

Quadro 4 - Universidades classificadas entre as Top 20 do mundo da edição de 2014, nos rankings internacionais ARWU, THE e QS

\begin{tabular}{|c|c|c|c|}
\hline UNIVERSIDADES & $\begin{array}{c}\text { ARWU } \\
2014\end{array}$ & $\begin{array}{l}\text { THE } \\
2014\end{array}$ & $\begin{array}{c}\text { QS } \\
2014\end{array}$ \\
\hline Harvard University & 1 & 2 & 4 \\
\hline Stanford University & 2 & 4 & 7 \\
\hline Massachusetts Institute of Technology (MIT) & 3 & 6 & 1 \\
\hline University of California-Berkeley & 4 & 8 & - \\
\hline University of Cambridge & 5 & 5 & 2 \\
\hline Princeton University & 6 & 7 & 9 \\
\hline California Institute of Technology & 7 & 1 & 8 \\
\hline Columbia University & 8 & 14 & 14 \\
\hline University of Chicago & 9 & 11 & 11 \\
\hline University of Oxford & 9 & 3 & 5 \\
\hline Yale University & 11 & 9 & 10 \\
\hline University of California, Los Angeles & 12 & 12 & - \\
\hline Cornell University & 13 & 19 & 19 \\
\hline University of California, San Diego & 14 & - & - \\
\hline University of Washington & 15 & - & - \\
\hline University of Pennsylvania & 16 & 16 & 13 \\
\hline The Johns Hopkins University & 17 & 15 & 14 \\
\hline University of California, San Francisco & 18 & - & - \\
\hline $\begin{array}{c}\text { Swiss Federal Institute of Technology Zurich - EHT } \\
\text { Zuric }\end{array}$ & 19 & 13 & 12 \\
\hline $\begin{array}{l}\text { University College London } \\
\end{array}$ & 20 & - & 5 \\
\hline Imperial College London & - & 9 & 2 \\
\hline University of Toronto & - & 20 & 20 \\
\hline University of Michigan & - & 17 & - \\
\hline Duke University & - & 18 & - \\
\hline University of Toronto & - & 20 & - \\
\hline King's College London & - & - & 16 \\
\hline University of Edingurbh & - & - & 17 \\
\hline Ecole Polytechnique Fédérale de Lausanne (EPFL) & - & - & 17 \\
\hline
\end{tabular}

Fontes: Elaborado pelas autoras a partir de Academic Ranking World Universities(2014a);

Times Hihger Education (2014a) e Quacquarelli Symonds (2014a)

\subsection{ARWU}

Ao se analisar a participação das universidades brasileiras desde a primeira edição do ranking, ARWU (Quadro 5), em 2003, percebemos apenas quatro universidades classificadas: a USP, classificada entre as Top 200; a UFRJ e a UNICAMP, classificadas na faixa que compreende as Top 400; e a UNESP, entre as Top 500 do mundo. Com pequena variação nas faixas de classificação, essas foram as únicas universidades brasileiras incluídas pelo ARWU na lista 
das Top 500 até 2006. Em 2007 a UFMG foi classificada na faixa compreendida entre 403-510 pelo ranking e a UFRGS incluída pela primeira vez na lista das 500 melhores a partir de 2008. Desde então, a lista de universidades brasileiras incluídas no ARWU tem se mantido inalterada, passando de quatro universidades em 2003 para seis universidades na lista das Top 500 em 2014.

Quadro 5 - Universidades brasileiras por intervalo de posições no ranking ARWU (2003-2014)

\begin{tabular}{|l|c|c|c|c|c|c|c|c|c|c|c|c|}
\hline UNIVERSIDADES & $\mathbf{2 0 0 3}$ & $\mathbf{2 0 0 4}$ & $\mathbf{2 0 0 5}$ & $\mathbf{2 0 0 6}$ & $\mathbf{2 0 0 7}$ & $\mathbf{2 0 0 8}$ & $\mathbf{2 0 0 9}$ & $\mathbf{2 0 1 0}$ & $\mathbf{2 0 1 1}$ & $\mathbf{2 0 1 2}$ & $\mathbf{2 0 1 3}$ & $\mathbf{2 0 1 4}$ \\
\hline \multirow{2}{*}{ USP } & $152-$ & $153-$ & $101-$ & $102-$ & $102-$ & $101-$ & $101-$ & $101-$ & $102-$ & $101-$ & $101-$ & $101-$ \\
& 200 & 201 & 152 & 150 & 150 & 150 & 151 & 150 & 150 & 150 & 150 & 150 \\
\hline \multirow{2}{*}{ UFRJ } & $301-$ & $302-$ & $301-$ & $301-$ & $305-$ & $303-$ & $303-$ & $301-$ & $401-$ & $301-$ & $301-$ & $301-$ \\
& 350 & 403 & 400 & 400 & 402 & 401 & 401 & 400 & 500 & 400 & 400 & 400 \\
\hline \multirow{2}{*}{ UNICAMP } & $351-$ & $302-$ & $203-$ & $301-$ & $203-$ & $201-$ & $201-$ & $201-$ & $201-$ & $201-$ & $301-$ & $301-$ \\
& 400 & 403 & 300 & 400 & 304 & 302 & 302 & 300 & 300 & 300 & 400 & 400 \\
\hline \multirow{2}{*}{ UNESP } & $401-$ & $404-$ & $401-$ & $401-$ & $403-$ & $402-$ & $402-$ & $301-$ & $401-$ & $301-$ & $301-$ & $301-$ \\
& 450 & 502 & 500 & 500 & 510 & 503 & 501 & 400 & 500 & 400 & 400 & 400 \\
\hline \multirow{2}{*}{ UFMG } & & & & & $403-$ & $303-$ & $303-$ & $301-$ & $301-$ & $301-$ & $301-$ & $301-$ \\
& & & & & 510 & 401 & 401 & 400 & 400 & 400 & 400 & 400 \\
\hline \multirow{2}{*}{ UFRGS } & & & & & & $402-$ & $402-$ & $401-$ & $401-$ & $401-$ & $401-$ & $401-$ \\
& & & & & & 503 & 501 & 500 & 500 & 500 & 500 & 500 \\
\hline
\end{tabular}

Fonte: Elaborado pelas autoras a partir de Academic Ranking World Universities (2014a)

A edição de 2014 do ranking ARWU avaliou mais de 1.200 universidades, mas não apresentou muitas mudanças e reafirmou o domínio americano nas primeiras posições. Assim, ao longo dos 12 anos, praticamente não houve alteração das universidades incluídas no "grupo de elite" do ARWU (Santos, 2015). A Universidade de Harvard é considerada a melhor do mundo, encabeçando pelo $12^{\circ}$ ano consecutivo a lista das melhores universidades, sendo seguida pela Universidade de Stanford, o MIT e a Universidade da CalifórniaBerkeley - os Estados Unidos continuam na liderança do ranking das Top 20, com 16 universidades na lista. O Reino Unido é o outro país que integra o exclusivo grupo anglo-saxão das 20 melhores universidades do mundo.

A América Latina possui 10 universidades classificadas na edição de 2014 do ARWU (seis são brasileiras), mas nenhuma delas dentro do Top 100. Apenas duas universidades latino-americanas estão classificadas entre as Top 
200, a Universidade de São Paulo (USP) e a Universidade de Buenos Aires, na Argentina. A Universidade Nacional Autónoma do México (201-300) está entre as Top 300, e as outras quatro universidades latino-americanas estão classificadas na faixa compreendida entre 400-500, dentre elas, duas universidades são chilenas: Universidade Católica do Chile (401-500) e Universidade do Chile.

Para a edição 2014 do ranking ARWU (Quadro 6) foram analisadas 29 universidades brasileiras, e seis delas $(20,6 \%)$ foram classificadas - ou seja, o desempenho foi praticamente o mesmo da edição anterior. Das universidades brasileiras classificadas a melhor colocada é a USP, que aparece na faixa entre 101-150, e é a única universidade ibero-americana entre as 150 melhores do mundo. As outras instituições de ensino superior do Brasil, no ARWU 2014, são a Universidade Federal do Rio de Janeiro (UFRJ), a Universidade Estadual de Campinas (UNICAMP), a Universidade Estadual Paulista (UNESP), e a Universidade Federal de Minas Gerais (UFMG), classificadas na faixa entre 301-400, e a Universidade Federal do Rio Grande do Sul (UFRGS), classificada na faixa entre 401-500 do ranking.

Quadro 6 - Universidades brasileiras classificadas entre as 500 no ranking ARWU, edição 2014

\begin{tabular}{|c|c|c|c|}
\hline $\mathbf{2 0 1 3}$ & VARIAÇÃO & $\mathbf{2 0 1 4}$ & UNIVERSIDADES \\
\hline $101-150$ & $=$ & $101-150$ & Universidade de São Paulo \\
\hline $301-400$ & $=$ & $301-400$ & Universidade Federal do Rio de Janeiro \\
\hline $301-400$ & $=$ & $301-400$ & Universidade Estadual de Campinas \\
\hline $301-400$ & $=$ & $301-400$ & Universidade Estadual Paulista \\
\hline $301-400$ & $=$ & $301-400$ & Universidade Federal de Minas Gerais \\
\hline $401-500$ & $=$ & $401-500$ & $\begin{array}{c}\text { Universidade Federal do Rio Grande } \\
\text { do Sul }\end{array}$ \\
\hline
\end{tabular}

Fonte: Elaborado pelas autoras a partir de Academic Ranking World Universities (2014a)

Considerando que as posições ocupadas por essas universidades são determinadas pelos indicadores analisados pelo ranking, além do posicionamento da universidade no ranking global é importante que se considere 
também a pontuação obtida pelas universidades brasileiras nos indicadores e em relação à instituição melhor posicionada no ranking.

Gráfico 1 - Comparação da pontuação obtida por USP e Harvard nos indicadores do ranking ARWU $2014^{5}$

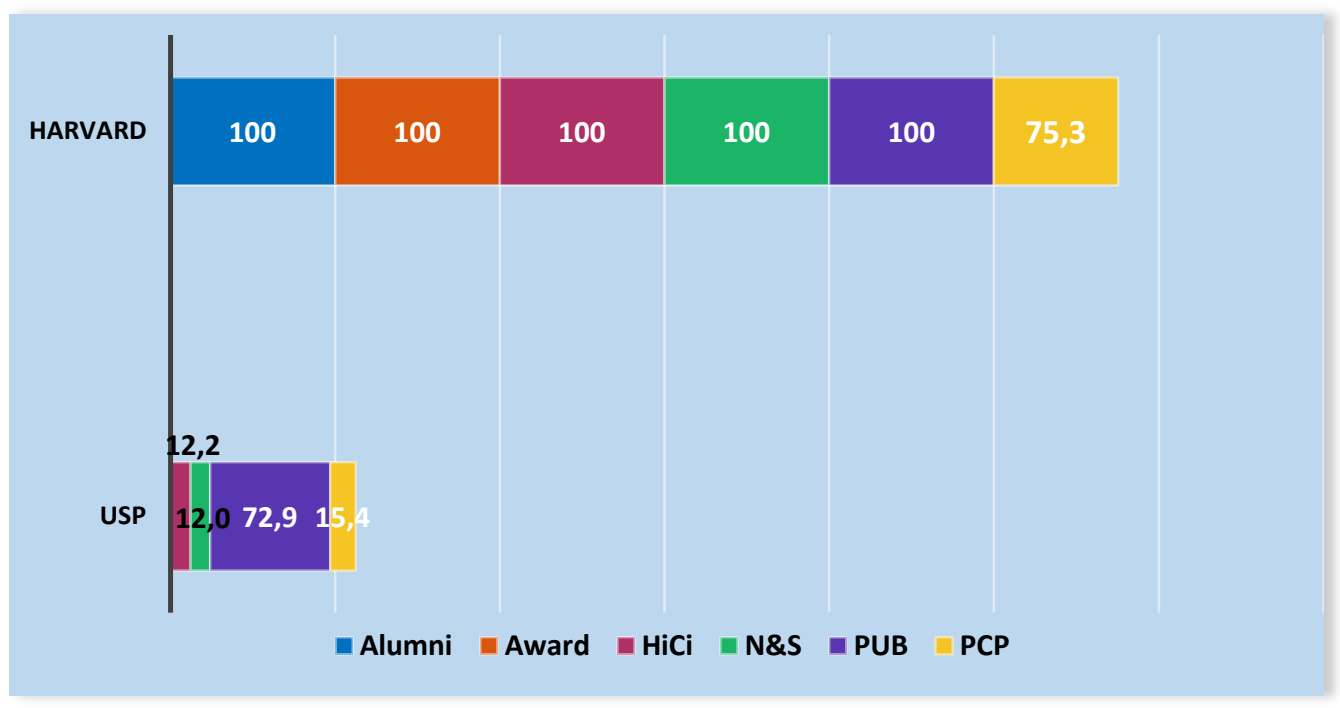

Fonte: Elaborado pelas autoras a partir de Academic Ranking World Universities (2014a)

O Gráfico 1 apresenta a pontuação obtida pela USP, melhor colocada entre as universidades brasileiras, tomando como referência a pontuação obtida pela Universidade de Harvard, que ocupa a primeira posição. A USP não pontuou nos indicadores Alumni e Award (Prêmios Nobel ou Medalhas Fields e alunos e professores), e a pontuação alcançada nos demais indicadores é bastante baixa. A maior diferença de pontuação entre a USP e a Universidade de Harvard se dá nos indicadores N\&S - publicações em Nature e Science (88 pontos de diferença) e HiCi - pesquisadores altamente citados (87,8 pontos de diferença). Esses dois indicadores têm peso de $20 \%$ cada um na pontuação final do ranking. A menor diferença entre USP e Harvard está no indicador PUB publicações na WoS, onde a diferença entre as duas instituições é de apenas 27,1 pontos. Essas diferenças posicionam a USP cerca de 150 posições de distância da Harvard. 
Gráfico 2 - Pontuação obtida pelas universidades brasileiras nos indicadores do ranking ARWU $2014^{6}$

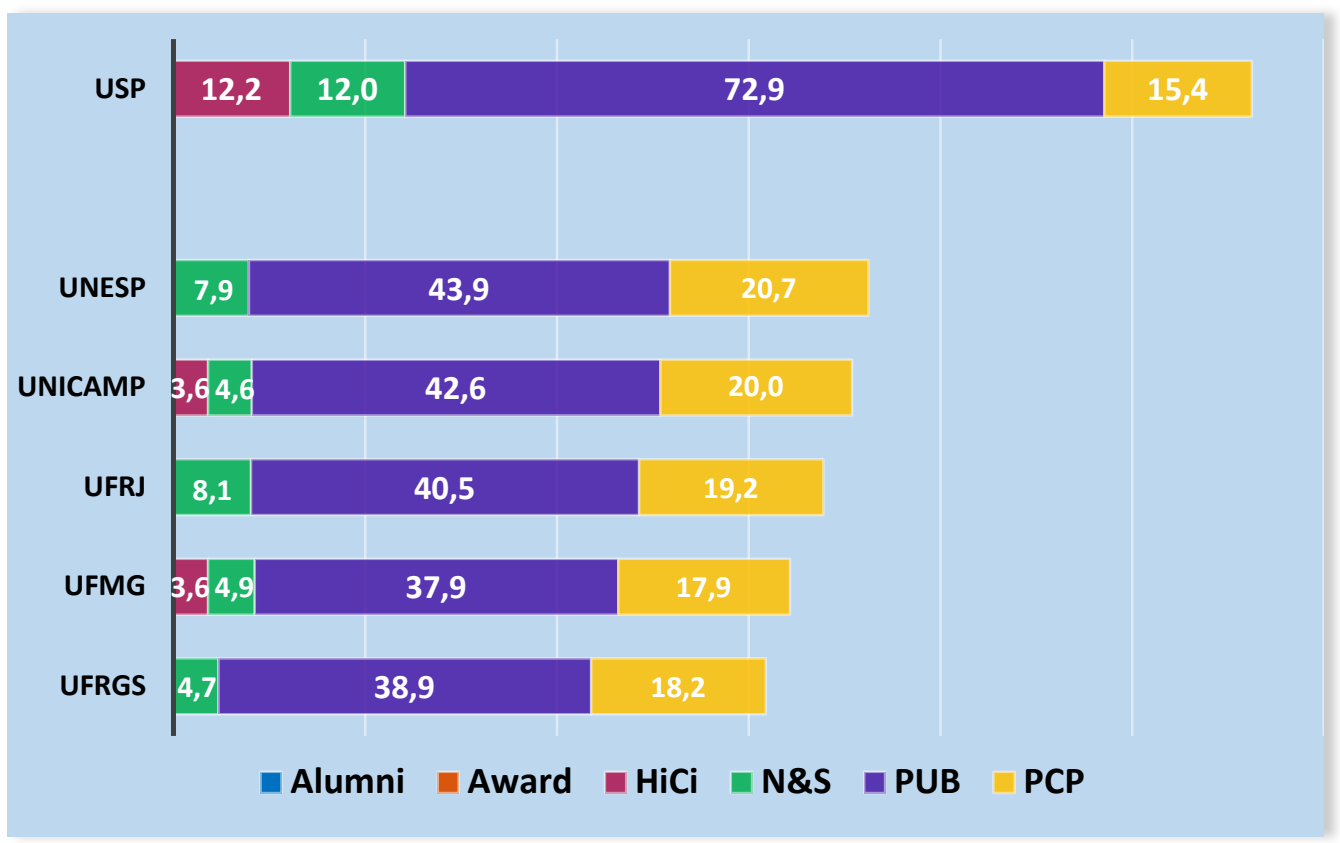

Fonte: Elaborado pelas autoras a partir de Academic Ranking World Universities (2014a)

Considerando apenas a pontuação obtida por cada universidade brasileira nos indicadores analisados pelo ranking ARWU (Gráfico 2), observa-se que ainda que não seja possível determinar sua posição exata, a USP, classificada na faixa que vai da $101^{\circ}$ a $150^{\circ}$ posição, é claramente a instituição com maior pontuação nos indicadores do ranking PUB - número de publicações indexadas na base WoS no último ano (20\%), HiCi - pesquisadores na lista dos mais citados (20\%), N\&S -publicação em Nature e Science nos últimos cinco anos (20\%) e ponderação dos indicadores anteriores pelo número de professores de tempo integral da instituição.

Embora as outras quatro universidades UFRJ, UNICAMP, UNESP e UFMG estejam classificadas na mesma faixa (301-400), elas podem ser diferenciadas entre si a partir de seu desempenho nos indicadores do ranking. Guardadas as devidas proporções, UNESP e UFRJ possuem perfil parecido em termos de pontuação em publicações na WoS e publicação em revistas Nature $e$ Science; as duas instituições não pontuaram em pesquisadores altamente citados, sendo que a UNESP pontua mais que a UFRJ em número de publicações e na ponderação dos indicadores pelo número de pesquisadores. A 
UNICAMP e a UFMG também apresentam perfil parecido - as duas instituições possuem pontuações muito similares em pesquisadores muito citados e publicações em revistas Nature e Science, sendo que a UNICAMP alcança pontuação maior em publicações e na ponderação por pesquisador. Por fim a UFRGS possui perfil parecido ao da UNESP e da UFRJ, mas com pontuação bem menor em todos os indicadores, foi classificada na faixa entre $401^{\mathrm{a}}$ e $500^{\mathrm{a}}$ posição no ranking geral.

É importante destacar que a menos que se calcule a pontuação final de todas as universidades classificadas no intervalo de posições dentro da faixa considerada, não é possível determinar com precisão a posição de classificação da universidade. Isso porque o ARWU somente indica a pontuação final das primeiras 100 universidades, as demais aparecem em grupos de 50 ou de 100 e ordenadas alfabeticamente, ou seja, não estão apresentadas por pontuação. Ainda assim, ignorando esse fato, o que se percebe é que com base apenas na ordem de apresentação das universidades dentro da faixa, os meios de comunicação costumam divulgar a posição "exata" da universidade, disseminando a informação e fazendo, inclusive, considerações sobre perda ou ganho de posições das universidades (USP, 2014; GASPARINI, 2014; O DIA, 2014) - um engano comum, que pode levar tanto o público em geral quanto tomadores de decisão a obterem interpretações equivocadas.

Diante dessa circunstância, com o intuito de determinar a posição exata de algumas universidades classificadas por faixas, bem como expandir resultados de classificação do ranking ARWU para universidades iberoamericanas não classificadas por esse ranking, Domingos Docampo (2013) desvelou os mecanismos de ponderação e operações matemáticas do ARWU, o que lhe permitiu reproduzir os resultados e classificar qualquer universidade segundo os parâmetros desse ranking. Desde então, o pesquisador faz anualmente o exercício de calcular a posição das universidades de Portugal, Espanha, América Latina e Caribe para cada nova edição do ranking ARWU (DOCAMPO, 2013). 
O desempenho das universidades brasileiras em rankings internacionais

Solange Maria dos Santos, Daisy Pires Noronha

Quadro 7 - Universidades brasileiras classificadas entre as 500 no ranking ARWU, edição 2014

\begin{tabular}{|c|c|c|}
\hline ARWU 2014 & DOCAMPO 2014 & UNIVERSIDADES \\
\hline $101-150$ & 134 & Universidade de São Paulo \\
\hline $301-400$ & 331 & Universidade Estadual Paulista \\
\hline $301-400$ & 344 & Universidade Estadual de Campinas \\
\hline $301-400$ & 366 & Universidade Federal do Rio de Janeiro \\
\hline $301-400$ & 389 & Universidade Federal do Rio Grande do Sul \\
\hline $401-500$ & 419 &
\end{tabular}

Fonte: Elaborado pelas autoras a partir de Academic Ranking World Universities (2014a) e Docampo (2014)

Segundo a classificação expandida do ARWU 2014, produzida por Docampo (Quadro 7), a posição das universidades brasileiras por pontuação final no ranking global é a seguinte: a USP com uma pontuação final calculada $(21,5)$, ocupa $134^{\mathrm{a}}$ posição no mundo, sendo a melhor universidade iberoamericana classificada pelo ARWU. A segunda universidade brasileira melhor posicionada é a UNESP, classificada na $331^{\text {a }}$ posição; a UNICAMP ocupa a

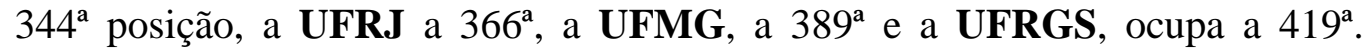
Segundo a classificação expandida produzida por Docampo (2014), as posições resultantes são bem diferentes das amplamente divulgadas nos meios de comunicação (SANTOS, 2015; USP, 2014; GASPARINI, 2014; O DIA, 2014).

A respeito da pontuação e do posicionamento das universidades no ranking, é importante destacar que, em todos os casos, a pontuação obtida pelas universidades é sempre relativa, isto é, proporcional à instituição classificada na primeira posição do ranking. A lista ordenada de universidades apresentadas pelo ARWU indica em que medida uma universidade, em particular, está próxima ou se assemelha à universidade classificada na primeira posição, no caso, à Universidade de Harvard. Sendo assim, a posição que uma universidade ocupa no ranking num determinado ano não depende apenas de seu desempenho, pois sua posição pode ser afetada, positiva ou negativamente, pelo que fizeram ou deixaram de fazer as outras universidades em relação aos aspectos avaliados pelo ranking. 
Dessa forma, o cenário aqui apresentado pode modificar-se significativamente para a próxima edição do ranking ARWU. Em 12 de agosto de 2014, o brasileiro Artur Ávila, pesquisador do IMPA e do Centre National de la Recherche Scientifique (CNRS), na França, foi o primeiro latino-americano agraciado com o "Nobel de Matemática" a Medalha Fields (MORAES, 2014). O pesquisador graduou-se na UFRJ, o que significa que a universidade será a única Instituição de Ensino Superior brasileira a pontuar no indicador Alumni alunos que obtiveram bacharelado, mestrado, ou doutorado na instituição (peso de 10\%) e que foram agraciados com Prêmio Nobel ou Medalha Fields. Em vista disso, a expectativa brasileira é saber como a posição das universidades brasileiras será afetada na próxima edição do ranking Xangai, agora que o Brasil possui um pesquisador agraciado com a Medalha Fields.

\subsection{THE}

Como o segundo ranking global de universidades a surgir no cenário internacional, publicado pela primeira vez em 2004, o THE foi de certa forma uma "resposta" ao lançamento do ARWU, em 2003. Ao longo das seis edições do THE-QS, apenas três universidades brasileiras (USP, UNICAMP e UFRJ) foram incluídas entre as instituições classificadas pelos THE-QS, sendo que na edição inaugural de 2004, nenhuma universidade brasileira foi incluída na lista das 200 classificadas pelo ranking.

Quadro 8 - Universidades brasileiras por intervalo de posições no ranking THE (2004-2014)

\begin{tabular}{|c|c|c|c|c|c|c|c|c|c|c|c|}
\hline UNIVERSIDADES & $\mathbf{2 0 0 4}$ & $\mathbf{2 0 0 5}$ & $\mathbf{2 0 0 6}$ & $\mathbf{2 0 0 7}$ & $\mathbf{2 0 0 8}$ & $\mathbf{2 0 0 9}$ & $\mathbf{2 0 1 0}$ & $\mathbf{2 0 1 1}$ & $\mathbf{2 0 1 2}$ & $\mathbf{2 0 1 3}$ & $\mathbf{2 0 1 4}$ \\
\hline USP & & 196 & 284 & 175 & 196 & 207 & & 178 & 158 & $226-250$ & $201-225$ \\
\hline UNICAMP & & & & 177 & 249 & 295 & & $276-300$ & $251-275$ & $301-350$ & $301-350$ \\
\hline UFRJ & & & & & 334 & 383 & & & & & \\
\hline
\end{tabular}

Fonte: Elaborado pelas autoras a partir de Times Higher Education Supplement (2014a)

Ao longo desse período, a USP figurou entre as Top 200 em três edições (2005, 2007 e 2008), a UNICAMP foi incluída na lista das 200 primeiras na edição de 2007 e a UFRJ foi classificada apenas nas edições de 2008 e de 2009. 
A partir de 2011, apenas duas universidades brasileiras, a USP e a UNICAMP, foram incluídas entre as instituições classificadas pelo THE, sendo que na sua edição inaugural da nova fase, em 2010, não consta nenhuma universidade brasileira. No período 2010-2014, a USP figurou entre as Top 200 em duas edições (2011 e 2012); em 2013 a universidade ficou entre as 250 primeiras; em 2014, foi classificada entre as 225 primeiras do ranking. A UNICAMP foi incluída entre as Top 300 em duas edições (2011 e 2012), e em 2013 e 2014 figurou entre as 300 do mundo segundo o ranking THE.

No ranking THE, os Estados Unidos, com 15 universidades, lideram a lista das 20 primeiras universidades na edição de 2014, com o Instituto de Tecnologia da Califórnia ocupando pelo quarto ano consecutivo o topo da lista das 400 instituições classificadas. O Reino Unido e a Alemanha também são destaque, com 12 universidades. A América Latina, por sua vez, possui apenas quatro universidades classificadas na edição de 2014 do THE, sendo duas brasileiras (USP e UNICAMP), uma do Chile (Universidade Técnica Federico Santa Marí) e outra da Colômbia (Universidade dos Andes), mas nenhuma delas classificada entre as Top 100.

Quadro 9 - Universidades brasileiras classificadas entre as 400 no ranking THE, edição 2014

\begin{tabular}{|c|c|c|c|}
\hline $\mathbf{2 0 1 3}$ & VARIAÇÃO & $\mathbf{2 0 1 4}$ & UNIVERSIDADES \\
\hline $226-250$ & +25 & $201-225$ & Universidade de São Paulo \\
\hline $301-350$ & $=$ & $301-350$ & Universidade Estadual de Campinas \\
\hline
\end{tabular}

Fonte: Elaborado pelas autoras a partir de Times Hihger Education (2014a)

$\mathrm{O}$ ranking THE não informa $\mathrm{o}$ total de universidades que foram avaliadas para a edição 2014. Os critérios de exclusão indicam apenas que universidades sem cursos de graduação e com publicação menor que mil artigos no período 2008 à 2012 (200 por ano) são desconsideradas. Na edição 2014, o ranking THE classificou duas universidades brasileiras, sendo que a melhor colocada, a USP, que no ano anterior havia sido classificada na faixa 226-250, subiu para a faixa 201-225, tornando-se a única universidade latino-americana entre as 225 primeiras do mundo. A UNICAMP manteve-se na mesma faixa de 
classificação, ficando entre as 350 universidades do mundo segundo o THE 2014.

O Gráfico 3 apresenta a pontuação obtida pela USP nos indicadores considerados pelo ranking, tomando como referência a pontuação obtida pelo do Instituto de Tecnologia da Califórnia (CALTHEC), que ocupa a primeira posição, sendo a instituição em função da qual as demais universidades estão ordenadas no THE 2014.

Gráfico 3 - Comparação da pontuação obtida por USP e CALTHEC nos indicadores do ranking THE 2014

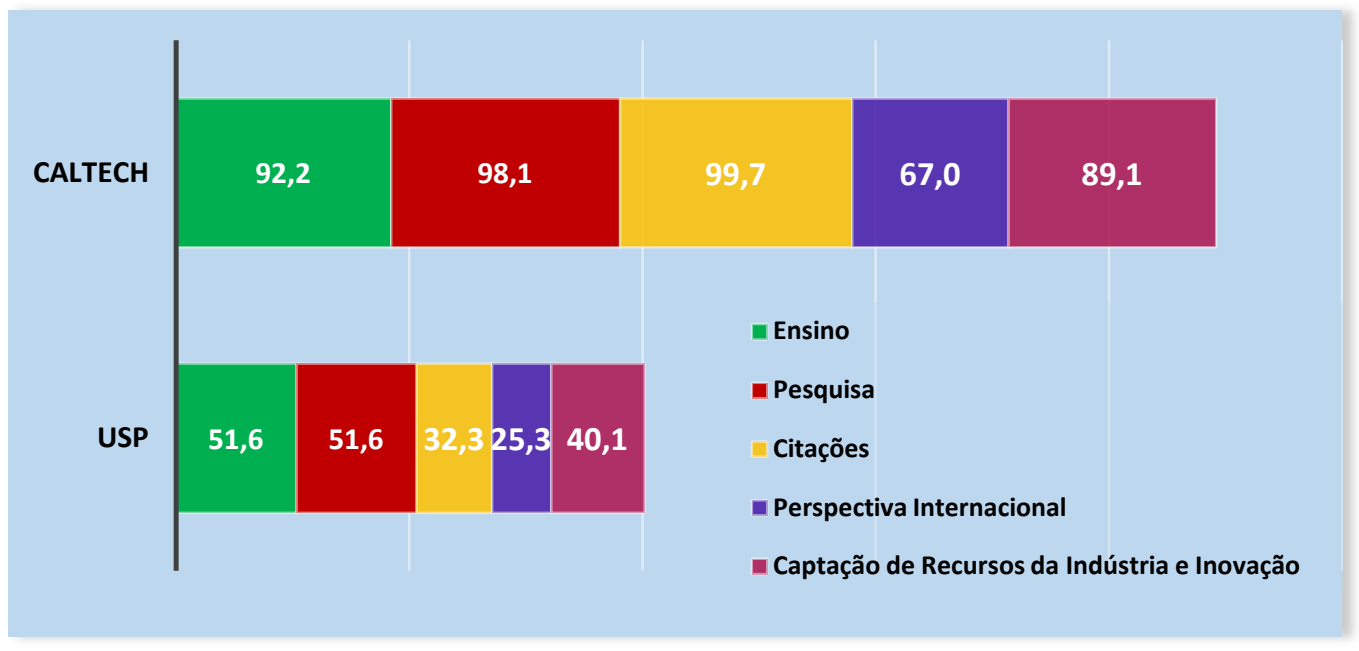

Fonte: Elaborado pelas autoras a partir de Times Hihger Education (2014a)

Considerando a pontuação obtida pela USP nas cinco dimensões, podese perceber que a diferença entre as duas instituições nas pontuações em alguns dos indicadores varia entre 40 e 49 pontos, sendo que a maior distância entre a USP e o CALTECH se dá quando observamos o indicador de citações $(67,4$ pontos de diferença). Vale lembrar que esse é o indicador ${ }^{7}$ de maior peso (30\%) no ranking THE. Nas dimensões ensino e pesquisa (com peso de $30 \%$ cada), importantes categorias sensíveis à pesquisa de opinião, a diferença é de $15 \%$ e $18 \%$, respectivamente. Neste aspecto, a diferença entre a USP e o CALTECH é menor (40,6 pontos em ensino e 46,5 pontos em pesquisa) que a diferença entre as duas instituições no indicador citações. Menores diferenças de desempenho nos indicadores e nas demais dimensões, associadas à diferença mais significativa na dimensão citações são o que determinam que a USP esteja 
posicionada a uma distância de mais de 200 posições da CALTECH no ranking THE.

Gráfico 4 - Pontuação obtida das universidades brasileiras nos indicadores do ranking THE 2014

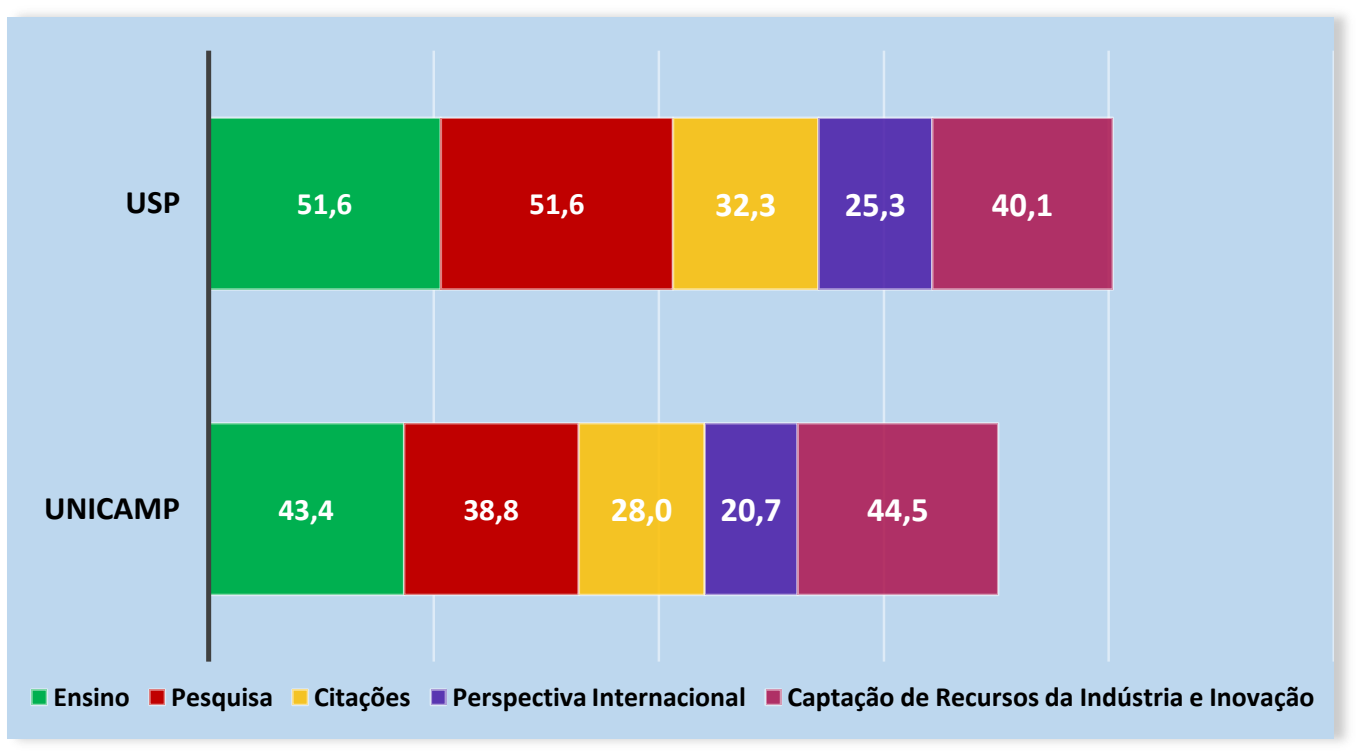

Fonte: Elaborado pelas autoras a partir de Times Hihger Education (2014a)

Examinando apenas as duas universidades brasileiras classificadas, é possível perceber que a partir do perfil de desempenho nos indicadores, as diferenças de pontuação entre USP e UNICAMP no ranking THE não são muito grandes. A maior distância está na dimensão pesquisa, com uma diferença de 12,8 pontos em favor da USP. A segunda dimensão com maior diferença é ensino, em que a USP obteve uma pontuação 8,2 acima da UNICAMP. Nas demais dimensões, a diferença é relativamente pequena (4,4 pontos). A UNICAMP obteve pontuação superior à USP apenas na dimensão captação de recursos da indústria: inovação, no entanto, essa é a dimensão com menor peso no ranking: $2,5 \%$. De modo geral nos rankings, a partir da $200^{\mathrm{a}}$ posição, a diferença de pontuação entre as instituições costuma ser muito pequena, sendo agrupadas por faixas. As diferenças de desempenho nos indicadores entre USP e UNICAMP, ainda que em alguns casos sejam pequenas, em conjunto explicam o fato de a USP estar classificada na faixa 201-225, a uma distância de mais de 100 posições da UNICAMP. 
Considerando que não se sabe ao certo o total de universidades analisadas, nem o número de instituições brasileiras consideradas nesse processo, que o THE possui apenas 400 posições disponíveis e que o ranking adota metodologia ancorada numa bateria de 13 indicadores (incluindo critério subjetivo de reputação 33\%), é muito difícil julgar qual desses fatores, ou a combinação deles, são determinantes para a baixa classificação das universidades brasileiras. No entanto, os resultados indicam que no caso do ranking THE é o desempenho no indicador citações, mais até do que no dos indicadores que avaliam a perspectiva internacional e o relacionamento com a indústria, o principal entrave que impede as universidades brasileiras de alcançarem melhores posições.

Os resultados apresentados mostram que o desempenho das universidades no ranking THE é muito tímido. Com base nos critérios de exclusão declarados, boa parte das universidades brasileiras estaria apta a ser analisada para inclusão no ranking, no entanto, sua inclusão depende da pontuação atingida, uma vez que o ranking global dispõe de apenas 400 posições. Assim, das universidades existentes (cerca de 18.000), o ranking tem capacidade de classificar somente cerca de $2 \%$ das universidades do mundo e classifica apenas $1,03 \%$ das universidades brasileiras.

\subsection{QS}

No ranking QS, a evolução da classificação das universidades brasileiras no período de 2010 a 2014 mostra que a USP, a UNICAMP e a UFRJ foram as universidades brasileiras que alcançaram as melhores posições nas cinco edições realizadas. Em 2010, apenas seis universidades brasileiras foram incluídas - a USP e a UNICAMP, que ficaram entre as Top 300. A UFRJ, a UFMG e a PUCRJ foram classificadas na faixa de 50 posições entre 501-550. A UNESP, classificada na faixa 551-600, completa a lista de universidades brasileiras incluídas entre as 600 classificadas pelo QS. Na edição seguinte, em 2011, o número de universidades brasileiras já havia dobrado, passando de seis para 12, e atualmente, o ranking QS classifica 22 universidades brasileiras. 
O desempenho das universidades brasileiras em rankings internacionais

Solange Maria dos Santos, Daisy Pires Noronha

Quadro 10 - Universidades brasileiras por intervalo de posições no ranking QS (2010-2014)

\begin{tabular}{|c|c|c|c|c|c|}
\hline UNIVERSIDADES & 2010 & 2011 & 2012 & 2013 & 2014 \\
\hline USP & 253 & $169=$ & 139 & 127 & 132 \\
\hline UNICAMP & 292 & 235 & 228 & 215 & 206 \\
\hline UFRJ & 381 & 381 & 333 & $284=$ & 271 \\
\hline UNESP & $551-600$ & $501-550$ & $551-600$ & $491-500$ & $421-430$ \\
\hline UNIFESP & & $401-450$ & $401-450$ & $411-420$ & $421-430$ \\
\hline UFMG & $501-550$ & $501-550$ & $451-500$ & $481-490$ & $451-460$ \\
\hline UFRGS & & $501-550$ & $501-550$ & $501-550$ & $471-480$ \\
\hline PUC-RJ & $501-550$ & $551-600$ & $551-600$ & $551-600$ & $501-550$ \\
\hline UNB & & $551-600$ & $551-600$ & $551-600$ & $551-600$ \\
\hline PUC-SP & & $501-550$ & $551-600$ & $551-600$ & $551-600$ \\
\hline UFSCAR & & $601+$ & $601+$ & $601-650$ & $551-600$ \\
\hline UFBA & & & & $601-650$ & $601-650$ \\
\hline PUC-RS & & & & $651-700$ & $651-700$ \\
\hline UFSC & & $601+$ & $601+$ & $651-700$ & $651-700$ \\
\hline UFPR & & & & $651-700$ & $651-700$ \\
\hline UFV & & & & $601-650$ & $701+$ \\
\hline UERJ & & & & $701+$ & $701+$ \\
\hline UEL & & & & $701+$ & $701+$ \\
\hline UFSM & & & & $701+$ & $701+$ \\
\hline UFC & & & & $701+$ & $701+$ \\
\hline UFPE & & & & $701+$ & $701+$ \\
\hline UFF & & & & & $701+$ \\
\hline
\end{tabular}

Fontes: Elaborado pelas autoras a partir de Quacquarelli Symonds (2014a)

Os critérios e as fontes de dados utilizados pelo QS parecem favorecer a maior representatividade das universidades brasileiras no ranking. Vale lembrar que o ranking THE inclui apenas duas universidades brasileiras dentre as 400 que classifica, e o ranking ARWU inclui apenas seis universidades do Brasil, sendo que desde 2008 nenhuma nova universidade brasileira é incluída entre as 500 classificadas (QUACQUARELLI SYMONDS, 2014b; QUACQUARELLI SYMONDS, 2014c).

A lista de instituições que ocupam as primeiras posições no ranking QS praticamente não sofreu alteração nenhuma desde sua edição inicial em 2010 
(SANTOS, 2015). Desta forma, como costuma ocorrer nas primeiras posições dos rankings globais, a edição de 2014 do ranking QS também mostra a hegemonia das universidades americanas e britânicas entre as Top 20 instituições de ensino do mundo. Em 2014, o MIT lidera, pelo terceiro ano consecutivo, a lista das 800 instituições classificadas pelo QS. Considerando a América Latina, quatro países participam do grupo daqueles que possuem universidades classificadas entre as Top 200, sendo eles o Brasil (USP), o Chile (Pontificia Universidad Católica de Chile), o México (Universidad Nacional Autónoma de México) e a Argentina (Universidad de Buenos Aires). Entre as Top 300 do ranking QS, o Brasil possui três universidades. Em 2014 o ranking QS avaliou mais de 3.500 universidades, sendo que 103 eram brasileiras, mas das quais apenas 22 (21,3\%) foram classificadas no ranking global, sendo 19 universidades públicas (14 federais e 5 estaduais) e 3 instituições privadas. Segundo a notação adotada, as universidades brasileiras classificadas pelo QS são, em sua maioria, instituições de grande porte (XL e L), num total de 17 $(77,2 \%) ; 21$ universidades $(95,4 \%)$ são de escopo generalista (com programas em todas as áreas do conhecimento, incluindo Medicina), sendo que oito universidades $(36,3 \%)$ dedicam-se à pesquisa de forma muito intensiva e 12 universidades $(54,5 \%)$ dedicam-se de forma intensiva.

Quadro 11- Universidades brasileiras classificadas no ranking QS, edição $2014^{8}$

\begin{tabular}{|c|c|c|c|c|c|c|c|c|}
\hline $\begin{array}{c}2013 \\
\text { POSIÇÃO }\end{array}$ & VARIAÇÃO & $\begin{array}{c}2014 \\
\text { POSIÇÃO }\end{array}$ & UNIVERSIDADES & TAMANHO & SCOPO & PESQUISA & IDADE & $\begin{array}{l}\text { PONTUAÇÃO } \\
\text { TOTAL }\end{array}$ \\
\hline 127 & -5 & $132=$ & $\begin{array}{l}\text { UNIVERSIDADE DE SÃO } \\
\text { PAULO (USP) }\end{array}$ & $\mathrm{XL}(>=30.000)$ & $\mathrm{FC}$ & VH & 4 & 63,9 \\
\hline 215 & +5 & $206=$ & $\begin{array}{c}\text { UNIVERSIDADE } \\
\text { ESTADUAL DE } \\
\text { CAMPINAS (UNICAMP) }\end{array}$ & $\mathrm{L}(>=12.000)$ & $\mathrm{FC}$ & VH & 3 & 53,5 \\
\hline $284=$ & +13 & 271 & $\begin{array}{l}\text { UNIVERSIDADE } \\
\text { FEDERAL DO RIO DE } \\
\text { JANEIRO }\end{array}$ & $\mathrm{XL}(>=30.000)$ & FC & VH & 4 & 44,5 \\
\hline $491-500$ & +70 & $421-430$ & $\begin{array}{c}\text { UNIVERSIDADE } \\
\text { ESTADUAL PAULISTA } \\
\text { "JÚLIO DE MESQUITA } \\
\text { FILHO" }\end{array}$ & $\mathrm{XL}(>=30.000)$ & $\mathrm{FC}$ & VH & 3 & 33,1 \\
\hline $411-420$ & -10 & $421-430$ & $\begin{array}{c}\text { UNIVERSIDADE } \\
\text { FEDERAL DE SÃO } \\
\text { PAULO (UNIFESP) }\end{array}$ & $\mathrm{M}(>=5.000)$ & $\mathrm{FC}$ & VH & 4 & 32,9 \\
\hline $481-490$ & +30 & $451-460$ & $\begin{array}{c}\text { UNIVERSIDADE } \\
\text { FEDERAL DE MINAS } \\
\text { GERAIS }\end{array}$ & $\mathrm{XL}(>=30.000)$ & $\mathrm{FC}$ & VH & 5 & 31,1 \\
\hline $501-550$ & +30 & $471-480$ & $\begin{array}{l}\text { UNIVERSIDADE } \\
\text { FEDERAL DO RIO } \\
\text { GRANDE DO SUL }\end{array}$ & $\mathrm{L}(>=12.000)$ & $\mathrm{FC}$ & VH & 5 & 30,7 \\
\hline $551-600$ & +50 & $501-550$ & $\begin{array}{c}\text { PONTIFICIA } \\
\text { UNIVERSIDADE } \\
\text { CATÓLICA DO RIO DE } \\
\text { JANEIRO - PUC - RIO }\end{array}$ & $\mathrm{L}(>=12.000)$ & $\mathrm{CO}$ & HI & 4 & \\
\hline $551-600$ & $=$ & $551-600$ & $\begin{array}{c}\text { PONTIFICIA } \\
\text { UNIVERSIDADE } \\
\text { CATÓLICA DE SÃO }\end{array}$ & $\mathrm{M}(>=5.000)$ & FC & MD & 4 & \\
\hline
\end{tabular}




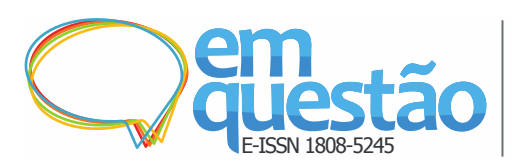

O desempenho das universidades brasileiras em rankings internacionais

Solange Maria dos Santos, Daisy Pires Noronha

\begin{tabular}{|c|c|c|c|c|c|c|c|c|}
\hline $\begin{array}{c}2013 \\
\text { POSIÇÃOO }\end{array}$ & VARIAÇÃO & $\begin{array}{c}2014 \\
\text { POSIÇÃOO }\end{array}$ & UNIVERSIDADES & TAMANHO & SCOPO & PESQUISA & IDADE & $\begin{array}{l}\text { PONTUAÇÃO } \\
\text { TOTAL }\end{array}$ \\
\hline & & & PAULO (PUC-SP) & & & & & \\
\hline $551-600$ & $=$ & $551-600$ & $\begin{array}{c}\text { UNIVERSIDADE DE } \\
\text { BRASILIA }\end{array}$ & $\mathrm{L}(>=12.000)$ & $\mathrm{FC}$ & $\mathrm{HI}$ & 4 & \\
\hline $601-650$ & +50 & $551-600$ & $\begin{array}{l}\text { UNIVERSIDADE } \\
\text { FEDERAL DE SÃO } \\
\text { CARLOS }\end{array}$ & $\mathrm{M}(>=5.000)$ & $\mathrm{FC}$ & VH & 3 & \\
\hline $601-650$ & $=$ & $601-650$ & $\begin{array}{c}\text { UNIVERSIDADE } \\
\text { FEDERAL DA BAHIA }\end{array}$ & $\mathrm{L}(>=12.000)$ & $\mathrm{FC}$ & $\mathrm{HI}$ & 4 & \\
\hline $651-700$ & $=$ & $651-700$ & $\begin{array}{c}\text { PONTIFICIA } \\
\text { UNIVERSIDADE } \\
\text { CATÓLICA DO RIO } \\
\text { GRANDE DO SUL }\end{array}$ & $\mathrm{M}(>=5.000)$ & $\mathrm{FC}$ & HI & 4 & \\
\hline $651-700$ & $=$ & $651-700$ & $\begin{array}{c}\text { UNIVERSIDADE } \\
\text { FEDERAL DE SANTA } \\
\text { CATARINA }\end{array}$ & $\mathrm{L}(>=12.000)$ & $\mathrm{FC}$ & $\mathrm{HI}$ & 4 & \\
\hline $651-700$ & $=$ & $651-700$ & $\begin{array}{c}\text { UNIVERSIDADE } \\
\text { FEDERAL DO PARANÁ } \\
\text { (UFPR) }\end{array}$ & $\mathrm{L}(>=12.000)$ & $\mathrm{FC}$ & $\mathrm{HI}$ & 5 & \\
\hline $701+$ & $=$ & $701+$ & $\begin{array}{l}\text { UNIVERSIDADE DO } \\
\text { ESTADO DO RIO DE } \\
\text { JANEIRO (UERJ) }\end{array}$ & $\mathrm{L}(>=12.000)$ & $\mathrm{FC}$ & HI & 4 & \\
\hline $701+$ & $=$ & $701+$ & $\begin{array}{l}\text { UNIVERSIDADE } \\
\text { ESTADUAL DE } \\
\text { LONDRINA }\end{array}$ & $\mathrm{L}(>=12.000)$ & $\mathrm{FC}$ & MD & 3 & \\
\hline $701+$ & $=$ & $701+$ & $\begin{array}{c}\text { UNIVERSIDADE } \\
\text { FEDERAL DE SANTA } \\
\text { MARIA }\end{array}$ & $\mathrm{L}(>=12.000)$ & $\mathrm{FC}$ & HI & 4 & \\
\hline $601-650$ & -100 & $701+$ & $\begin{array}{c}\text { UNIVERSIDADE } \\
\text { FEDERAL DE VIÇOSA }\end{array}$ & $\mathrm{L}(>=12.000)$ & $\mathrm{FC}$ & HI & 4 & \\
\hline $701+$ & $=$ & $701+$ & $\begin{array}{c}\text { UNIVERSIDADE } \\
\text { FEDERAL DO CEARÁ } \\
\text { (UFC) }\end{array}$ & $\mathrm{L}(>=12.000)$ & $\mathrm{FC}$ & HI & 4 & \\
\hline $701+$ & $=$ & $701+$ & $\begin{array}{l}\text { UNIVERSIDADE } \\
\text { FEDERAL DO } \\
\text { PERNAMBUCO } \\
\end{array}$ & $\mathrm{L}(>=12.000)$ & $\mathrm{FC}$ & $\mathrm{HI}$ & 4 & \\
\hline $651-700$ & -50 & $701+$ & $\begin{array}{c}\text { UNIVERSIDADE } \\
\text { FEDERAL FLUMINENSE }\end{array}$ & $\mathrm{L}(>=12.000)$ & $\mathrm{FC}$ & $\mathrm{HI}$ & 4 & \\
\hline
\end{tabular}

Nota: TAMANHO: XL - Extra Large (>= 30,000 estudantes); L - Large (>= 12,000 estudantes); M - Medium (>= 5,000 estudantes); SCOPO: FC - Full Comprehensive (Artes e Humanidades, Engenharia e Tecnologia, Ciências da Vida, Ciências Naturais e Ciências Sociais, e Medicina); CO - Comprehensive (Apenas as 5 grandes áreas. Não inclui Medicina).

PESQUISA - INTENSIDADE: VH - Very Hingh; HI - High; MD - Medium. IDADE: 5 -

Histórica ( $>=100$ anos); 4 - Madura ( $<100$ anos); 3 - Estabelecida ( $<50$ anos).

Fonte: Elaborado pelas autoras a partir de Quacquarelli Symonds (2014a)

Na última edição do QS, a USP alcançou a $132^{\mathrm{a}}$ posição, sendo a universidade brasileira melhor colocada, seguida pela UNICAMP, na 206 posição e a UFRJ, na $271^{a}$ posição. As demais universidades classificadas entre as Top 500, que também receberam pontuação final no ranking QS são: UNESP (421-430), UNIFESP (421-430), UFMG (451-460) e a UFRGS (471-480). A pontuação das universidades brasileiras nos indicadores do ranking QS é analisada no Gráfico 5. 
Gráfico 5 - Comparação da pontuação obtida por USP e MIT nos indicadores do ranking QS 2014

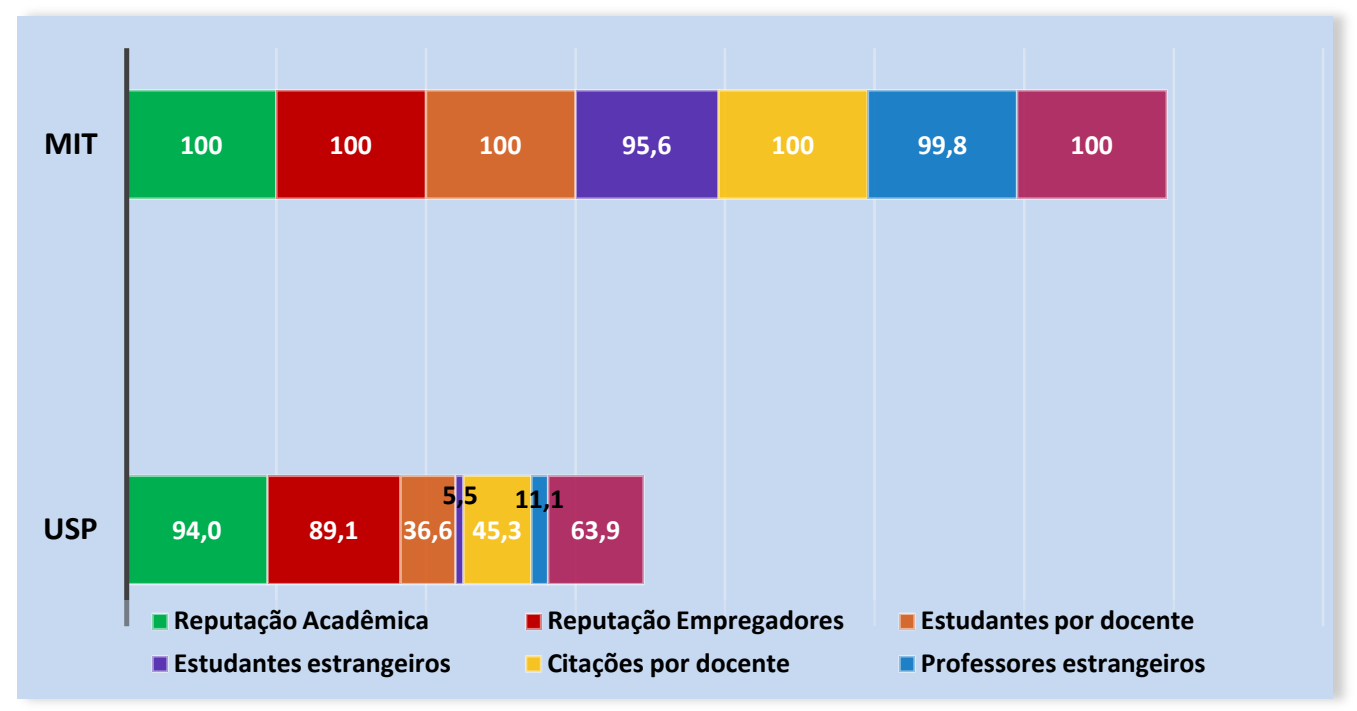

Fonte: Elaborado pelas autoras a partir de Quacquarelli Symonds (2014a)

O Gráfico 5 apresenta a pontuação obtida pela universidade brasileira melhor posicionada, a USP, nos oito indicadores considerados pelo ranking, tomando como referência a pontuação obtida pelo MIT, que ocupa a primeira posição, em função da qual as demais universidades são ordenadas no QS 2014. Considerando a pontuação obtida pelas universidades brasileiras, a USP apresenta diferenças grandes em relação ao MIT em alguns casos. No indicador reputação acadêmica (40\%), por exemplo, a distância entre USP e MIT é de seis pontos, enquanto no indicador reputação entre empregadores (10\%) a diferença é de 10,9 pontos. A maior diferença entre a USP e o MIT se dá quando observamos os indicadores que buscam analisar a universidade do ponto de vista da internacionalização, aqui entendida como a proporção de estudantes e de professores estrangeiros. Nesses indicadores, a distância entre as duas instituições é de respectivamente 90,1 e 88,7 pontos. No entanto, como o peso desses indicadores é de $5 \%$ cada um, eles possuem pouco impacto na pontuação final do ranking. Já no indicador citações por docente (20\%), a pontuação da USP foi 54,7 pontos menor; no indicador proporção de estudantes por docente (20\%), a diferença entre USP e MIT é de 63,4 pontos. Contudo, o peso desses indicadores na pontuação final do ranking é muito maior. Considerando que de modo geral nos rankings pequenas diferenças podem influenciar 
significativamente na classificação final, ainda que não sejam astronômicas, as diferenças de desempenho da USP nos indicadores empregados pelo QS resultam numa pontuação final de 36,1 pontos menor, situando-a a uma distância de 131 posições da instituição líder, o MIT.

Gráfico 6 - Pontuação obtida pelas universidades brasileiras nos indicadores do ranking QS 2014

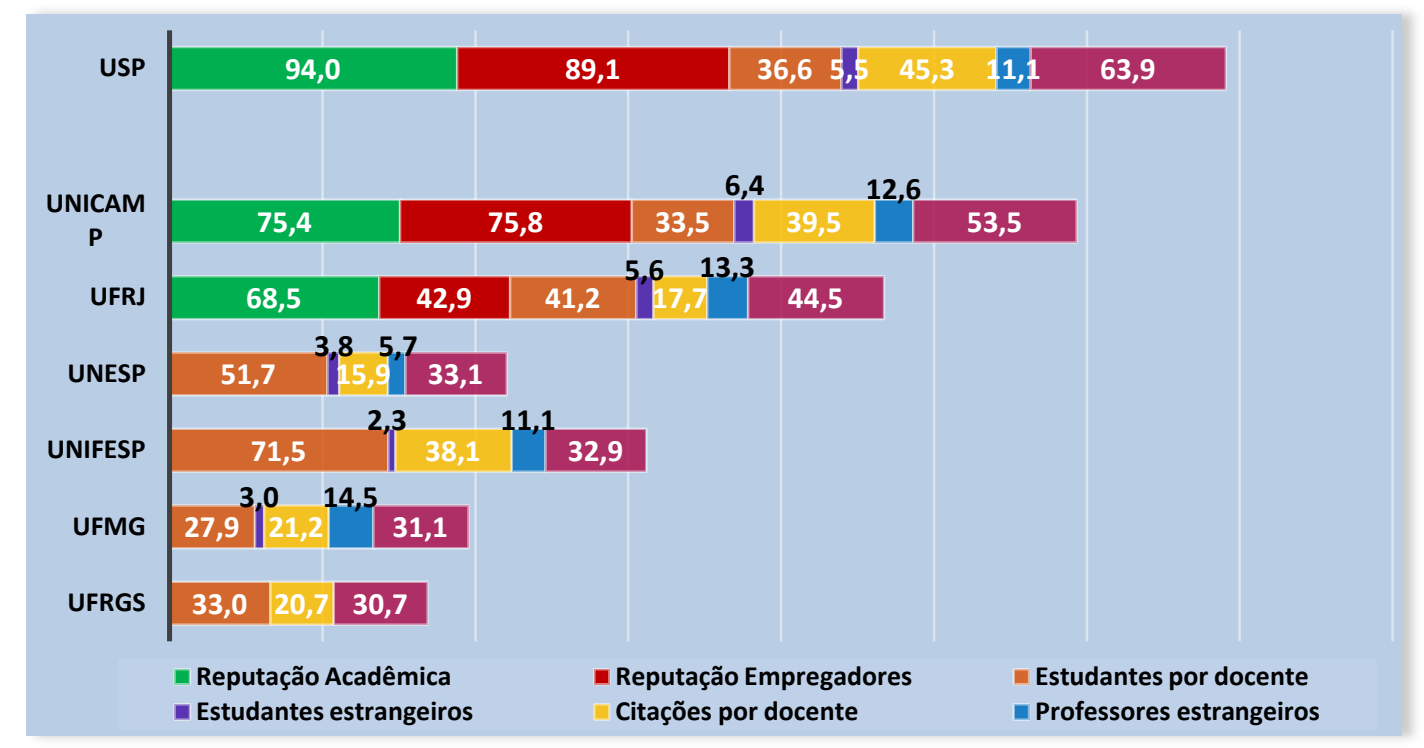

Fonte: Elaborado pelas autoras a partir de Quacquarelli Symonds (2014a)

Examinando apenas as três universidades brasileiras melhor classificadas, é possível perceber a partir do perfil de desempenho nos indicadores, guardadas as devidas proporções, que essas universidades possuem perfis parecidos. Ao observarmos os indicadores empregados no ranking, percebemos que as diferenças mais significativas de pontuação entre a USP, a UNICAMP e a UFRJ estão nos indicadores de reputação acadêmica e reputação entre empregadores, que juntos são responsáveis por $50 \%$ da pontuação final do ranking. Em reputação acadêmica, a USP obteve 18,6 pontos acima da UNICAMP e 25,5 pontos acima da UFRJ. Já em reputação entre os empregadores, a USP obteve 13,3 pontos acima da UNICAMP e 46,7 pontos acima da UFRJ. Os indicadores citações por docente e proporção de estudantes por docente juntos somam $40 \%$ da pontuação final. Em citações por docente, a USP atinge 5,6 pontos acima da UNICAMP e 27,6 pontos acima da UFRJ; em proporção de estudantes por docente, a UFRJ obteve 4,6 pontos 
acima da USP e 7,7 pontos acima da UNICAMP. Nos demais indicadores com menor peso, as diferenças entre as três universidades é relativamente pequena. Em conjunto, as diferenças de desempenho nos indicadores do ranking colocam a USP entre as 140 primeiras, a UNICAMP, entre as 210 primeiras e a UFRJ entre as 280 melhores universidades do mundo (Gráfico 6).

Considerando as demais universidades brasileiras classificadas e com pontuação disponível (UNESP, UNIFESP, UFMG e UFRGS), mais do que as respectivas diferenças de pontuação nos indicadores, o que chama atenção é o fato de que nenhuma delas tenha recebido pontuação em reputação acadêmica e reputação entre os empregadores. No entanto, essas universidades aparecem listadas entre as melhores do mundo em algumas disciplinas do ranking QS por áreas, em que um dos critérios de inclusão é justamente a reputação. Dentre universidades nessa situação, cabe destacar a UNIFESP, que além de obter significativa pontuação nos indicadores estudantes por docente (71,5 pontos) e citações por docente (38,1 pontos) no ranking geral, no ranking por áreas classificou-se entre as Top 100 em Farmácia e Farmacologia, ficou entre as 150 melhores em Medicina e entre as Top 200 em Ciências Biológicas, mas não recebeu pontuação em pesquisa de opinião com acadêmicos e empregadores.

Ao longo desse estudo pode-se perceber que a evolução das classificações das universidades brasileiras nos principais rankings internacionais (Quadro 12) ratifica a existência de viés dos mesmos na direção do modelo anglo-saxão de universidades de pesquisa. As universidades dos Estados Unidos, do Reino Unido e de alguns países da Europa Ocidental predominam em todas as classificações.

Quadro 12 - Lista das universidades brasileiras classificadas nos rankings QS, ARWU e THE, edição 2014

\begin{tabular}{|c|c|c|c|}
\hline UNIVERSIDADES & QS 2014 & ARWU 2014 & THE 2014 \\
\hline USP & 132 & $101-150$ & $201-225$ \\
\hline UNICAMP & 206 & $301-400$ & $301-350$ \\
\hline UFRJ & 271 & $301-400$ & - \\
\hline UNESP & $421-430$ & $301-400$ & - \\
\hline UNIFESP & $421-430$ & - & - \\
\hline UFMG & $451-460$ & $301-400$ & - \\
\hline UFRGS & $471-480$ & $401-500$ & - \\
\hline PUC-RJ & $501-550$ & - & - \\
\hline UNB & $551-600$ & - & \\
\hline
\end{tabular}




\begin{tabular}{|c|c|c|c|}
\hline UNIVERSIDADES & QS 2014 & ARWU 2014 & THE 2014 \\
\hline PUC-SP & $551-600$ & - & - \\
\hline UFSCAR & $551-600$ & - & - \\
\hline UFBA & $601-650$ & - & - \\
\hline PUC-RS & $651-700$ & - & - \\
\hline UFSC & $651-700$ & - & - \\
\hline UFPR & $651-700$ & - & - \\
\hline UERJ & $701+$ & - & - \\
\hline UEL & $701+$ & - & - \\
\hline UFSM & $701+$ & - & - \\
\hline UFV & $701+$ & - & - \\
\hline UFC & $701+$ & - & - \\
\hline UFPE & $701+$ & - & - \\
\hline UFF & $701+$ & - & - \\
\hline
\end{tabular}

Fontes: Elaborado pelas autoras a partir de Academic Ranking World Universities (2014a); Times Hihger Education (2014a) eQuacquarelli Symonds (2014a)

A comparação dos resultados e a classificação das universidades brasileiras nos três rankings internacionais mostra que há pouca concordância entre os rankings quanto ao número de universidades incluídas e às posições que ocupam em cada uma das classificações. A maior concordância entre esses rankings se dá na classificação da USP como a melhor universidade brasileira.

O ARWU, um dos rankings mais elitistas e de maior prestígio, em 2003 classificava apenas quatro universidades brasileiras (SANTOS, 2015), mas na edição de 2014 foram incluídas seis universidades brasileiras entre as top 500 do ranking. Os rankings THE e QS, que possuem metodologia análoga e empregam tanto indicadores objetivos (bibliométricos) quanto subjetivos (pesquisa de reputação), divergem consideravelmente quanto ao número de universidades classificadas - em 2014 o QS classificou 20 universidades a mais que o THE. Assim, do ponto de vista da representatividade das universidades brasileiras nos rankings internacionais, pode-se dizer que o QS demonstra ser o ranking mais "inclusivo", ao passo que o THE, que classifica apenas duas universidades brasileiras, demonstra ser o mais "excludente".

Podem ser verificados resultados mais discrepantes ao se observar a posição de classificação da UNESP - que apesar de ser a $6^{\text {a }}$ melhor universidade dentro do ranking nacional, ocupar a $271^{\mathrm{a}}$ posição no $\mathrm{QS}$, ser a $2^{\mathrm{a}}$ melhor colocada no ARWU (empatada na 301-400ª posição com UNICAMP e UFRJ), não foi classificada pelo THE. 
A comparação de posições das universidades brasileiras nos rankings mostra que apenas duas universidades brasileiras (USP e UNICAMP) foram classificadas dentro dos três rankings internacionais considerados neste estudo. A UFRJ, a UNESP, a UFMG e a UFRGS foram classificadas em dois (QS e ARWU) dos rankings, ao passo que as demais 16 universidades foram classificadas apenas pelo ranking QS. Além de ser o ranking que classifica o maior número de universidades brasileiras, o QS também foi o que concedeu melhor classificação à UNICAMP (206 ${ }^{\mathrm{a}}$ posição) e à UFRJ (271 ${ }^{\mathrm{a}}$ posição) na edição de 2014. Em edições anteriores, essas universidades também alcançaram boas colocações na classificação realizada pelo QS (SANTOS, 2015).

As posições alcançadas pelas universidades é um reflexo da pontuação obtida por cada uma delas na bateria de indicadores empregados por cada ranking. A análise dessa pontuação mostrou que na maioria dos rankings, as universidades brasileiras destacam-se por sua alta pontuação no indicador volume de publicações, e em alguns casos também no indicador reputação entre acadêmicos e empregadores. Por outro lado, as pontuações mais baixas foram obtidas nos indicadores que medem impacto por meio de publicações altamente citadas, indicador que costuma ter alto peso na maioria dos rankings. As universidades brasileiras também registram baixa pontuação em indicadores que analisam aspectos como perspectiva internacional, interação com a indústria e inovação, mas esses indicadores possuem pesos mais baixos nos rankings internacionais.

Dado o que foi exposto, pode-se considerar que o desempenho das universidades brasileiras frente às metodologias dos rankings internacionais ainda é bastante tímida.

\section{Considerações finais}

Pouco mais de uma década se passou desde o surgimento do primeiro ranking no cenário mundial. A partir de então, um grande número de rankings tem sido publicado anualmente, seus resultados gerando uma pressão significativa tanto sobre as universidades ao redor do mundo quanto sobre os ministérios e 
instituições responsáveis por acompanhar o desempenho das universidades nos rankings globais.

Por sua semelhança com tabelas de classificação, habitualmente utilizadas em esportes, ao resumir atividades e aspectos complexos das universidades em um único número, os rankings passam imagem enganosa de simplicidade. A aparente clareza oferecida por eles faz com que muitas vezes se acredite que a posição das instituições em um determinado ranking reflete com precisão sua qualidade, o que pode levar a interpretações equivocadas tanto por parte do público em geral e dos meios de comunicação, quanto por parte de gestores públicos. Em função das razões que lhes dão origem e dos objetivos particulares de cada um, os rankings são comparações baseadas em somas ponderadas de um conjunto limitado de indicadores. Como não existe um conjunto de critérios amplos ou unanimemente aceitos para medir a qualidade das universidades, ao selecionar, privilegiar e atribuir peso a um indicador ou a um conjunto de indicadores, cada ranking apresenta sua visão do que considera qualidade. Sendo assim, é importante ter em mente que os rankings não são instrumentos neutros, mas construídos e utilizados intencionalmente para fins e contextos específicos. Portanto, esses dispositivos não devem ser observados com visão simplista ou utilizados acriticamente. É importante conhecer seus objetivos, alcance e limitações para que não sejamos conduzidos a falsas interpretações e decisões superficiais a partir da compreensão limitada deles.

Autoridades e gestores desprevenidos sobre as características metodológicas dos rankings podem interpretar mal seu significado e cair na "tentação" de querer modificar o valor de um indicador para subir de posição num determinado ranking, em vez de melhorar a qualidade de sua instituição como um todo (HAZELKORN, 2010). O aperfeiçoamento das universidades não está em modificar o valor de um indicador, mas sim em modificar condições, práticas e culturas institucionais que aumentem as possibilidades de melhores respostas frente à sua missão institucional. Sendo assim, sistemas de classificação não são instrumentos de melhoria - podem servir ao debate político macro em algumas áreas específicas, mas não são suficientes para o desenvolvimento das universidades. 
Embora os rankings internacionais exerçam certo fascínio sobre gestores e formuladores de políticas, é importante agir com muita cautela quando se trata de implementar estratégias visando impulsionar as universidades que mais se destacam dentro das classificações internacionais. Há uma crença crescente de que com a liderança e os investimentos adequados, as universidades existentes podem ser drasticamente transformadas em instituições de classe mundial em um período relativamente curto. Nesse sentido, formular políticas de investimento e de apoio dirigidas apenas à melhoria considerável e em curto prazo, valorizando apenas o posicionamento das universidades de "elite" em rankings internacionais, pode acabar favorecendo um pequeno grupo de instituições, que receberiam a maior concentração de recursos e esforços, acabando por promover desigualdades e penalizando o sistema universitário como um todo.

O fato do Brasil não figurar entre os países mais bem colocados não significa que não exista produção científica importante ou centros de excelência de pesquisa. É necessário considerar que as classificações internacionais são, de modo geral, homogeneizadoras e, sendo assim, há muitas particularidades, nuances, e bolsões de excelência em áreas específicas que não são capturadas pelos rankings internacionais quando avaliam as instituições dos diferentes países como um todo.

\section{Referências}

ALTBACH, P. G. (Ed.). Leadership for world-class universities: challenges for developing countries. New York: Routledge, 2010.

ACADEMIC RANKING OF WORLD UNIVERSITIES. Academic Ranking of World Universities (2003-2014). 2014a. Disponível

em: <http://www.shanghairanking.com>. Acesso em: 13 jul. 2014.

ACADEMIC RANKING OF WORLD UNIVERSITIES. Methodology. 2014b Disponível em: <http://www.shanghairanking.com/ARWU-Methodology2014.html>. Acesso em: 13 jul. 2014.

ACADEMIC RANKING OF WORLD UNIVERSITIES. About Academic Ranking of World Universities. c2014c. Disponível em: $<$ http://www.shanghairanking.com/aboutarwu.html >. Acesso em: 13 jul. 2014. 
DILL, D. D. Convergence and diversity: the role and influence of university rankings (Keynote Address presented at the Consortium of Higher Education Researchers. In: ANNUAL RESEARCH CONFERENCE, 19th, 2006, Kassel. Disponível

em: $<$ https://www.researchgate.net/publication/225084106_Convergence and D iversity The role and influence_of university_rankings $>$. Acesso em: 13 ago. 2014.

DOCAMPO, D. Reproducibility of the Shanghai academic ranking of world universities results. Scientometrics, Budapest, v. 94, n. 2, p. 567-587, 2013.

DOCAMPO, D. Shanghai Ranking Expanded 2014 ed. c2014. Disponível em: <http://dicits.ugr.es/rankinguniversidades/wpcontent/uploads/2014/05/ShanghaiRanking_EXPANDED_Iberoamericanas_2014-.pdf>. Acesso em: 23 Set. 2014.

HAZELKORN, E. Os rankings e a batalha por excelência de classe mundial: estratégias institucionais e escolhas de políticas. Revista Ensino Superior Unicamp, Campinas, n. 1, p. 43-64, abr. 2010. Disponível em:

<http://www.gr.unicamp.br/ceav/revistaensinosuperior/ed01_maio2010/pdf/Ed0 1 _marc 02010_ranckings.pdf>. Acesso em: 08 maio 2012.

GASPARINI, Claudia. As 15 melhores universidades do mundo em 2014. Exame.com, São Paulo, 15 ago. 2014. Carreira. Disponível em: <http://info.abril.com.br/noticias/carreira/fotonoticias/as-15-melhoresuniversidades-do-mundo-em-2014.shtml>. Acesso em: 09 dez. 2014.

MORAES, F. T. Brasileiro ganha a Medalha Fields, considerada o "Nobel da Matemática". Folha de São Paulo, 12 de agosto de 2014. Ciência. Disponível em: <http://www1.folha.uol.com.br/ciencia/2014/08/1499290-brasileiro-ganhaa-medalha-fields-considerada-o-nobel-da-matematica.shtml>. Acesso em: 3 nov. 2014.

SEIS universidades brasileiras estão entre as 500 melhores do mundo. O Dia, Rio de Janeiro, 15 ago. 2014. Disponível em:

<http://odia.ig.com.br/noticia/brasil/2014-08-15/seis-universidades-brasileirasestao-entre-as-500-melhores-do-mundo.htmll>. Acesso em: 9 dez. 2014.

QUACQUARELLI SYMONDS. QS World University Rankings: Previous Years Ranking Results and Digital supplements (2010-2014). 2014a. Disponível em <http://www.topuniversities.com/qs-world-university-rankings>. Acesso em: 13 out. 2014.

QUACQUARELLI SYMONDS. QS World University Rankings: Methodology. 2014b. Disponível em:

<http://www.topuniversities.com/university-rankings-articles/world-universityrankings/qs-world-university-rankings-methodology>. Acesso em: 13 jul. 2014. 
QUACQUARELLI SYMONDS. Policies \& Conditions: inclusion in rankings. 2014c. Disponível em: <http://www.iu.qs.com/universityrankings/policies-conditions $>$. Acesso em: 13 jul. 2014.

RAUHVARGERS, A. Global university rankings and their impacts: report I. Brussels: European University Association, 2011. (EUA Report on Rankings 2011). Disponível em:

<http://www.eua.be/pubs/Global_University_Rankings_and_Their_Impact.pdf> . Acesso em: 07 abr. 2012.

RAUHVARGERS, A. Global university rankings and their impact: report II. Brussels: European University Association, 2013.

SAISANA, M.; D’HOMBRES, B.; SALTELLI, A. Rickety numbers: volatility of university rankings and policy implications. Research Policy, Amsterdam, v. 40, n. 1, p. 165-177, 2011.

SALMI, J.; SAROYAN, A. League tables as policy instruments: uses and misuses. Higher Education Management and Policy, Paris, v. 19, n. 2, p. 3168, 2007.

SANTOS, S. M. O desempenho das universidades brasileiras nos rankings internacionais: áreas de destaque da produção científica brasileira. 2015. 341p.Tese (Doutorado) - Escola de Comunicações e Artes, Universidade de São Paulo, São Paulo. 2015.

TIMES HIGHER EDUCATION. World university rankings (2004-2014). 2014a. Disponível em: <https://www.timeshighereducation.com/worlduniversity-rankings >. Acesso em: 13 jul. 2014.

TIMES HIGHER EDUCATION. World university rankings 2014-2015 methodology. 2014b. Disponível em:

<http://www.timeshighereducation.co.uk/world-university-rankings/201415/world-ranking/methodologymethodology>. Acesso em: 13 jul. 2014.

USP sobe duas posições e fica em $144^{\circ}$ lugar no ranking ARWU. Universidade de São Paulo [portal], São Paulo, 15 ago. 2014. Sala de Imprensa. Disponível em: <http://www.usp.br/imprensa/?p=42138>. Acesso em: 09 nov 2014. 


\title{
The performance of Brazilian universities in international rankings
}

\begin{abstract}
Through the last ten years, world university rankings became very significant. The great value achieved lead them to a powerful role where they have influence over policies, evaluative processes, investment decisions and institutional reorganization. Thus, this study aims to analyze the performance of brazilian universities in three of the main global university rankings ARWU; THE and QS. This research revealed that Brazilian universities achieved better scores in indicators such as number of publications and academic and employer reputation. The lowest scores were obtained in the measuring impact indicators through highly cited publications, an indicator which usually it's of high concern in most rankings. It was concluded that in spite of these results, it's important to acknowledge that in general, most global rankings are homogenizing, and therefore, there are many peculiarities, nuances and pockets of excellence in specific areas that are not captured by international rankings when institutions are evaluated as a whole.
\end{abstract}

Keywords: Brazilian universities. Higher education institutions. Universities rankings.

Recebido: 03/06/2015

Aceito: $20 / 11 / 2015$

\footnotetext{
${ }^{1}$ Estudo desenvolvido como parte da tese de doutorado "O desempenho das universidades brasileiras nos rankings internacionais: áreas de destaque da produção científica brasileira" defendida no PPGCI, ECA/USP, Abr. 2015.

${ }^{2}$ No início, os rankings, também denominados league tables, eram elaborados por importantes meios de comunicação, dentre os quais se destacavam: Business Week, US News \& World Report, Financial Times, The Economist e o Wall Street Journal.

${ }^{3}$ Anteriormente denominado Institute of Higher Education da Shanghai Jiao Tong University. Desde 2009 a publicação do ARWU conta com o apoio da ShanghaiRanking Consultancy, uma consultoria independente não subordinada a nenhuma universidade ou agência do governo. Disponível em: <http://www.shanghairanking.com/aboutus.html>. Acesso em: 28 fev. 2014.

${ }^{4}$ Entre 2004 e 2009, o ranking foi produzido em colaboração com a empresa britânica Quacquarelli Symonds (QS).

${ }^{5}$ Alumni - alunos Prêmios Nobel ou Medalhas Fields; Award - professores Prêmios Nobel ou Medalhas Fields; HiCi - pesquisadores altamente citados; N\&S- artigos publicados na Nature ou na Science; PUB -publicações na WoS; PCP - desempenho acadêmico de acordo com o tamanho da instituição.
} 


\footnotetext{
${ }^{6}$ Alumni - alunos Prêmios Nobel ou Medalhas Fields; Award - professores Prêmios Nobel ou Medalhas Fields; HiCi - pesquisadores altamente citados; N\&S- artigos publicados na Nature ou na Science; PUB - publicações na WoS; PCP - desempenho acadêmico de acordo com o tamanho da instituição.

${ }^{7}$ Para a edição de 2014 foram examinadas as citações recebidas em seis anos (2008-2013) de artigos publicados entre 2008-2012 na base WoS.

${ }^{8}$ A partir da posição 700 as 100 instituições restantes são consideradas um único grupo, identificado como $700+$. Quando duas ou mais instituições obtém a mesma pontuação, a sua posição é acompanhada pelo sinal de igual (=) para indicar que esta é uma posição compartilhada por mais de uma universidade.
} 